\title{
The Combination of Market Value Data and Background Information Used to Analyze a Company or a Subfund
}

\author{
Jingqiu Liu
}

\author{
CNU high school, Beijing, 100048, China \\ Corresponding author's e-mail: Vivian.wang@cas-harbour.org
}

\begin{abstract}
With the development of economic globalization, more and more developing countries begin to make significant contribution to the world. As markets in these developing countries improve, these markets also show the characteristics of high economic development speed and great market development potential, which is valuable to research. Successful companies all have different directions and philosophies. However, people often do not pay attention to the direction of these companies' operations when investing, only to understand the indicators, financial results and market value of these companies. This passage analyzed and compared the economic data of equity, scale and the background information of three companies or subfunds(MASCX KB and FXI) to show people how to understand whether a company or a subfund is worth being indicated. The answer of that question is people should combine the information and historical data of a company.
\end{abstract}

Keywords: Value investing, Data analysis, company analysis, MACSX, Kookmin bank, FXI

\section{INTRODUCTION}

Investment is the prospect of people looking for a good and stable fund, but people cannot fully guarantee the price of the fund just volatility according to their imagination, so this uncertainty has led to people more cautious when investment. In order to minimize risk, people need to learn about the financial status of the fund, to understand the company's indicators, financial results and market value. But people often ignore the background information of the companies, like what are the company's products, when is the company on the market and what people expect of the company or fund.
The following three companies are selected for discussion, namely Matthews Asia(MACSX), Kookmin bank and FXI.

\section{BASIC ECONOMIC DATA}

According to the research online, MACSX's average market capitalization is $\$ 26.9$ billion [1]. The goal of investment for MACSX is seeking long-term capital growth. What's more, for MACSX, their credit rating is about -0.06 [1], which is not particularly high. The P/E of Matthews Asian Growth \& Income Fund; Investor (MACSX) is 17.54

\section{Equity Holdings}

\begin{tabular}{lcc} 
Average & MACSX & Category Average \\
\hline Price/Earnings & 17.54 & 14.9
\end{tabular}

Figure 1. Earnings price of MACSX 
In figure 1, 17.54 means the average price Matthews Asian Growth \& Income Fund get is 17.54 per fund, and the Category Average is 14.9 per fund. The P/E of Matthews Asian Growth \& Income Fund; Investor (MACSX)is larger than the Category average p/e, which means choosing MACSX probably can bring more benefits for buyers.
FXI has been one of the most stable funds studied in the past two years. For the past five years, with the exception of a few weeks, its volatility has been steady at $5 \%$ or less [1]. However, at the same time, even in recent years when the economic situation is better, it has not seen a significant increase in price. In figure 2 , the volatility of FXI is between 30 to 50 during past 4 years.

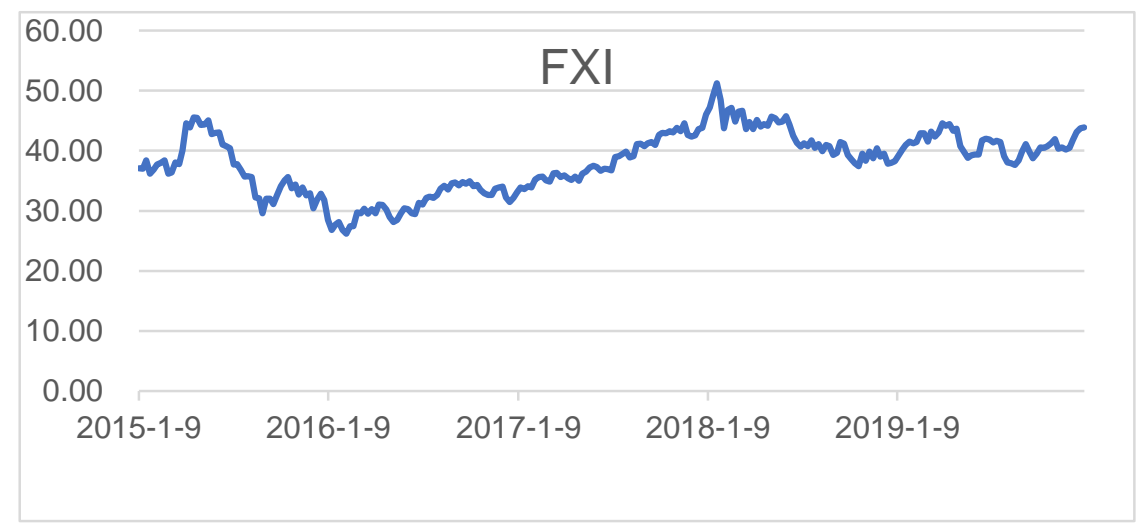

Figure 2. Price change of FXI

Kookmin bank rose steadily until 2017 , but has been falling slowly ever since. This may be caused by the manipulation of some chaebol in South Korea. This may also be the reason why its volatility is $24.73 \%$ [2]. The equity of KB have a large fluctuation between 20 to 60 .

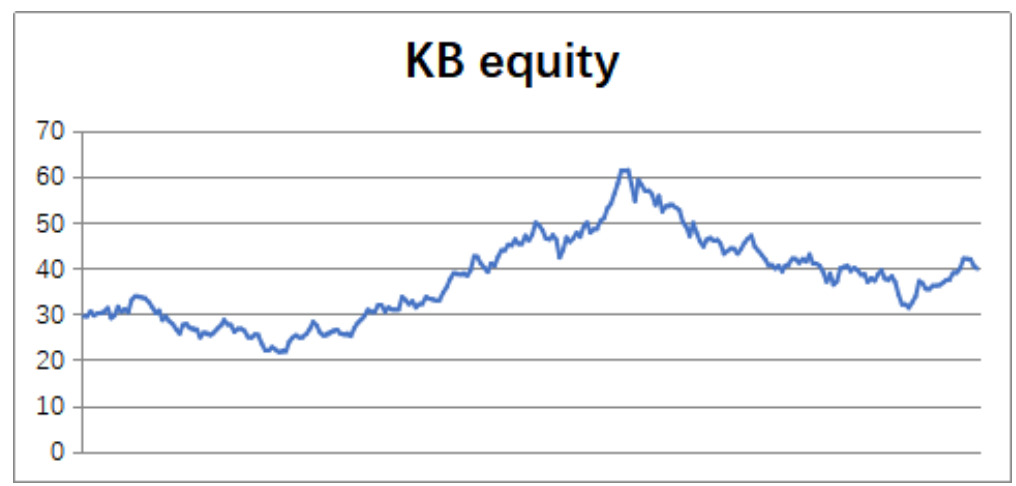

Figure 3. Equity of KB



Figure 4. Scaled of KB 


\section{BACKGROUND INFORMATION}

Matthews Asia was founded in 1991 in the belief that Asia offers investors unique long-term growth opportunities. The culture in this enterprise is that gain knowledge about investing from in-depth basic research and focus on identifying high-belief investment concepts that can last for years or even decades. The goal of investment for MACSX is seeking long-term capital growth [3]. What is more, for MACSX, their credit rating is about -0.06 , which is not particularly high. When the foundation was first established, they had a manager named Mr. Andrew Foster. He has done an excellent job during his tenure and has often brought many benefits to the foundation. However, after he left this foundation, a lot of workers in MACSX started worrying about the future of MACSX. Therefore, in conclusion, the introduction or entry of important fund members changes people's expectations of MACSX frequently.

Moreover, for Asian companies, Asia is also part of the emerging market. As a result, currency movements in Asia can have a big impact on the fund. For example, the Asian economic crisis in 1997. This financial crisis has had a direct impact on the MACSX. First of all, the value of the stock market fell by $20 \%$ to $50 \%$. What's more, the currency values also fall from $30 \%$ to $80 \%$ [1]. Consequently, rising and falling currencies in emerging markets have a big impact on markets.

Kookmin bank, as bank stock, will be influenced by the interest rate of the central bank, to be more specific, if central rate makes detailed policy to increase the interest rate, it will increase the conditions of the Kookmin bank and increase the value of Kookmin bank. In addition, the increase of reserve ratio will deteriorate the condition of the bank and decrease the value of it. Then, another factor may influence the value is the exchange rate. The increase of south Korean won exchange rate may increase the competition of the Kookmin bank and increase the value of Kookmin bank. And finally, some crisis such as 1998 Asian financial crisis or 2008 Global financial crisis will also decrease the value of Kookmin bank.

FXI is one of the brands of Guangzhou fashion coordinate clothing co., LTD., which is the essence of IBP group. IBP was founded in Chicago in 2002 and entered China in 2006. IBP with "innovation, excellence, power" for the idea, with the spirit of pioneering and innovative, keen market sense and indomitable perseverance, commitment to high-grade fashion protection of mobile devices, fashion briefcase, and ladies fashion handbags, and other products design, development, sales and service one-stop service, establish the international brand positioning [2].

FXI fashion coordinates was born in Chicago in 2002, which integrates the cultural and food landscape left over from the Midwest world. The founder, Mr. Tom Zheng, loves life and pursues "pleasure, elegance, texture and practicality" [4]. He is a Canadian Chinese who is a fashion maniac and an international designer. He has long seen the direction of globalization and laid the foundation for the rapid development of FXI. From this perspective, the introduction of important fund members, business philosophy and brand building of an enterprise often change people's expectations for it.

Moreover, as a company listed in China, FXI is also influenced by emerging markets in Asia. On the macro level, fluctuations in the exchange rate, financial situation and so on will affect people's expectations of the company. Specifically, the company's performance and credit rating also affect the FXI fund price.

\section{COMBINATION}

According to the analysis above, the three funds are very good economic foundation. People are unlikely to only use price volatility to find which fund they should invest, because price volatility is not a familiar thing for normal investors and they do not know what happen to this subfund, but with the analysis of the background, people can analyze what happen in daily life may affect fund, so as to decide whether not to invest in this fund.

\section{CONCLUSION}

This article mainly through the analysis of the basic situation of funds and background information to help people analyze whether the fund is worth investing in. However, it is impossible for people to analyze the basic economic situation and background information of a fund to adjust the trend of a fund. Whether a fund is worth investing needs more in-depth research and long-term observation. Besides, more comprehensive aspects need to be considered.

\section{ACKNOWLEDGMENT}

Thank for those people who study together with me and help me solve problems. Professor Sun, my teammates: Han Deng, Zizheng Wang, Xinyu Li, Yicheng Zhao and Jiayi Gong.

\section{REFERENCES}

[1] Data from: finance.yahoo.com/quote/MACSX

[2] Data from: msn.com/en-us/money/stockdetails/fia1tkf2

[3] Data from: www.kb-kookminbkcamb.com

[4] M.Hauskeller, T.D.Philbeck, C.D.Carbonell. The Palgrave handbook of posthumanism in film and television. Houndmills, Basingstoke, Hampshire: Palgrave Macmillan, 2015.

[5] R.O.Thomas. Terminated: The Life and Death of the Cyborg in Film and Television. The Palgrave 
Handbook of Posthumanism in Film and

Television,2015, 57-65. doi:

$10.1057 / 9781137430328 \_7$.

[6] D. Ayers. Chimeras and Hybrids: The Digital Swarms of the Posthuman Image. The Palgrave Handbook of Posthumanism in Film and Television,2015,99-108. doi:10.1057/9781137430328_11. 